CASA, Vol.9 n.1, julho de 2011

c

Cadernos de Semiótica Aplicada

Vol. 9.n.1, julho de 2011

Publicação SEMESTRAL

ISSN: 1679-3404

\title{
O CÍRCULO DE BAKHTIN E A PSICOLOGIA DE LEONTIEV: CONTRIBUIÇÕES PARA UMA INTERPRETAÇÃO DO CONCEITO DE GÊNEROS DISCURSIVOS
}

\author{
BAKHTIN CIRCLE AND LEONTIEF PSYCHOLOGY: \\ CONTRIBUTIONS TO AN INTERPRETATION OF THE DISCOURSE GENRES \\ CONCEPT
}

\author{
Rafael Henrique PALOMINO ${ }^{1}$ \\ UNESP - Faculdade de Ciências e Letras de Araraquara
}

\begin{abstract}
RESUMO: Este trabalho dedica-se a aproximar conceitos propostos pelo Círculo de Bakhtin (em sua filosofia da linguagem) e por A. N. Leontiev (em seus estudos de psicologia), com a pretensão de tecer algumas considerações sobre o conceito de gêneros do discurso. A relação entre as ideias desses pensadores coloca em destaque, principalmente, problemas relativos ao entendimento da subjetividade (em sua tensão com as coerções sociais operadas sobre o uso da língua), à historicidade dos gêneros do discurso, ao lugar do materialismo e da dialética na análise dos gêneros e ao conceito de refração, que pode ser mais bem entendido em relação com as contribuições de Leontiev. Evidente que se trata de muitas questões e, por isso, o presente artigo limita-se a algumas ponderações sobre esses temas.
\end{abstract}

PALAVRAS-CHAVE: Círculo de Bakhtin; Gêneros do discurso; Leontiev; Bakhtin; Voloshinov.

ABSTRACT: This paper dedicates itself to approach concepts proposed by the Bakhtin Circle (in his language philosophy) and by Leontief (in his psychology studies), intending to make some considerations about the concept of the discourse genres. The relation between these thinkers' ideas remarks, especially, problems related to the subjectivity comprehension (in its tension with the social coercions operated upon the language use), to the discourse genres historicity, to the places of materialism and dialectic in genre analysis, and to the concept of refraction, that can be better understood in relation with Leontief's contributions. Obviously, those are too many questions. Therefore, the present article is limited to some considerations about such themes.

KEYWORDS: Bakhtin’s Circle; Discursive genres; Leontief; Bakhtin; Voloshinov.

\section{Introdução}

No estudo da língua e de suas manifestações, não é nova a preocupação com o problema dos gêneros do discurso. Já desde a Antiguidade, eles atarefavam Aristóteles,

\footnotetext{
1 Aluno regularmente matriculado no Programa de Pós-Graduação em Linguística e Língua Portuguesa da UNESP de Araraquara.

Disponível em: http://seer.fclar.unesp.br/casa
} 
ocupado em analisar os gêneros poéticos e retóricos, e, durante muito tempo depois dele, essas discussões ainda perseveraram. $\mathrm{O}$ fato de esse tema não ter saído de foco nos estudos linguísticos por tanto tempo demonstra, de maneira mais que definitiva, a sua importância para todos os que se ocupam em compreender questões relativas à língua e a seu uso. A despeito dessa atenção que sempre lhe foi dedicada, porém, a noção de gêneros do discurso permaneceu, contraditoriamente, séculos restrita aos domínios traçados por Aristóteles, da retórica e da poética. Foi apenas no século XX, a partir dos estudos do Círculo de Bakhtin ${ }^{2}$, que a abrangência dessa noção se ampliou, adentrando outras esferas de utilização da língua. Os pensadores russos deram um valor nunca antes conferido ao tema, referindo-se a ele em diversos textos, e M. Bakhtin chegou mesmo a pretender dedicar um livro todo à questão. Embora essa pretensão não tenha sido levada adiante, dela restou um artigo, datado de 1953, básico para as muitas reflexões que, no século passado e no atual, fizeram-se e se fazem sobre os gêneros do discurso e sua importância nos estudos linguísticos. Esse artigo foi traduzido no Brasil com o nome de "Os gêneros do discurso" e é, junto com outros textos do Círculo de Bakhtin, a principal fonte de inspiração do trabalho que apresentamos aqui.

Pretendemos contribuir para a discussão sobre os gêneros de discurso, oferecendo uma interpretação da visão do Círculo de Bakhtin acerca deles e relacionando-a com as ideias do psicólogo russo A. N. Leontiev. Essa associação não é fortuita. Ela parte, em primeiro lugar, da constatação de vários pontos comuns entre o pensamento do psicólogo e dos autores do Círculo. Essas coincidências derivam, certamente, do fato de todos adotarem o marxismo como matriz para muitos de seus estudos. Essa fonte comum de que eles se valeram em suas reflexões é a segunda razão por que cremos ser razoável associá-los. Além disso, é normal verem-se as ideias do Círculo de Bakhtin associadas às de L. S. Vigotski que, como se sabe, era coordenador de um famoso grupo de pesquisadores (a chamada "Escola de Vigotski"), entre os quais estava Leontiev. Não há, pois, excentricidade alguma em aproximar esses estudiosos. Dessa aproximação, pretendemos extrair reflexões frutíferas sobre como surgem os gêneros do discurso, o modo concreto de existência deles, a forma de apropriação deles pelos falantes e, em especial, sobre a historicidade dos gêneros. Começaremos expondo brevemente o raciocínio do Círculo de Bakhtin sobre os gêneros do discurso; depois, aspectos da psicologia de Leontiev, para, então, fazermos ponderações aproximando os pensadores.

\section{Os gêneros do discurso no Círculo de Bakhtin}

A proposta do Círculo de Bakhtin que tornou tão importante seu entendimento dos gêneros do discurso é a de ampliar o alcance da noção de gênero. Essa proposta baseia-se na ideia de que tudo o que é dito realiza, em alguma medida, tipos "relativamente estáveis" de discurso. Nas palavras de Bakhtin (1997b, p. 279, grifo nosso):

A utilização da língua efetua-se em forma de enunciados (orais e escritos), concretos e únicos, que emanam dos integrantes duma ou doutra esfera da atividade humana. O enunciado reflete as condições específicas e as finalidades de cada uma dessas esferas, não só por seu conteúdo (temático) e

\footnotetext{
${ }^{2}$ Há uma conhecida polêmica sobre a autoria das obras do Círculo de Bakhtin, a respeito da qual precisamos nos posicionar. Como é certo que os autores do Círculo se influenciavam mutuamente, preferimos considerar as obras como resultantes das reflexões de todos eles. Mesmo aquelas cuja autoria se supõe certa são frutos da mútua influência dos autores do Círculo, e, por isso, tratá-las-emos, aqui, como resultado de um trabalho coletivo. Ao lidar com a autoria dessas obras, então, referir-nos-emos não a Bakhtin, Voloshinov ou a qualquer outro, mas ao Círculo de Bakhtin como um todo. Apenas ao citar trechos das obras, é que optamos, em respeito às normas técnicas da $\mathrm{ABNT}$, por fazer a referência com o nome daquele a quem a obra foi creditada.
} 
por seu estilo verbal, ou seja, pela seleção operada nos recursos da língua recursos lexicais, fraseológicos e gramaticais -, mas também, e sobretudo, por sua construção composicional. Estes três elementos (conteúdo temático, estilo e construção composicional) fundem-se indissoluvelmente no todo do enunciado, e todos eles são marcados pela especificidade de uma esfera de comunicação. Qualquer enunciado considerado isoladamente é, claro, individual, mas cada esfera de utilização da língua elabora seus tipos relativamente estáveis de enunciados, sendo isso que denominamos gêneros do discurso.

Se toda esfera de comunicação realiza seus gêneros, então se realiza um gênero sempre que se usa a língua, e não apenas quando se faz um uso, digamos, "especial" dela, como um uso poético ou retórico. O conceito de gênero do discurso extrapola, assim, os limites dos objetos de estudo tradicionais, e coloca-se nas mais diversas esferas de atividade humana. Os gêneros emanam dessas esferas e, por isso, pode-se depreender que eles têm uma existência concreta. Bakhtin (1997c, p. 142) mesmo viria a dizer isso, ao afirmar que "a linguagem de um gênero é histórica e concreta". Isso é importante, pois, se o gênero é concreto, então ele não pode ser um agrupamento de textos obtido por uma classificação taxionômica, mas um fato, perceptível (em graus variáveis de consciência) aos falantes de uma língua, que condiciona a produção dos enunciados. Esse condicionamento só pode ser de caráter normativo. $\mathrm{O}$ gênero funciona como uma referência para elaborar enunciados, estabelecendo limites às possibilidades da fala do enunciador e conduzindo-a no sentido da adequação a uma forma socialmente construída. Os enunciados, portanto, embora sejam individuais, realizam uma forma social, advinda de condicionamentos oriundos da atividade humana em que eles se engajam. Essa forma social do enunciado - o gênero - compõe-se de três elementos essenciais: conteúdo temático, estilo e construção composicional. Essa última consideração, presente no excerto que citamos acima (que é um trecho do artigo de 1953), já havia sido feita há muito em Bakhtin/Voloshinov (1999, p. 43, grifo nosso):

Mais tarde, em conexão com o problema da enunciação e do diálogo, abordaremos também o problema dos gêneros linguísticos. A este respeito faremos simplesmente a seguinte observação: cada época e cada grupo social têm seu repertório de formas de discurso na comunicação sócio-ideológica. A cada grupo de formas pertencentes ao mesmo gênero, isto é, a cada forma de discurso social, corresponde um grupo de temas. Entre as formas de comunicação (por exemplo, relações entre colaboradores num contexto puramente técnico), a forma de enunciação ("respostas curtas" na "linguagem de negócios") e, enfim, o tema, existe uma unidade orgânica que nada poderia destruir. Eis porque a classificação das formas de enunciação deve apoiar-se sobre uma classificação das formas da comunicação verbal. Estas últimas são inteiramente determinadas pelas relações de produção e pela estrutura sociopolítica.

Nesse excerto, escrito em 1929, o Círculo de Bakhtin já sintetizava os componentes fundamentais dos gêneros do discurso. R. Rojo (2005, p. 195) é quem demonstra isso. Segundo ela, o uso repetido da palavra "gênero", nesse excerto, mostra que os membros do Círculo estavam tratando, já em 1929, do mesmo assunto que os ocuparia em 1953. Mas há, neste tratamento, alguns detalhes a se observar. Segundo a autora (ibidem, p. 195, grifo nosso): 
[no excerto de Bakhtin/Voloshinov citado acima] a palavra gênero, antes qualificada de linguístico (que, nesse tema, opõe-se a literário ou poético) isto é, expande para a vida o que antes restringia-se à arte - equaciona-se a forma de discurso (social), forma da enunciação e subordina-se às formas da comunicação (verbal/sócio-ideológica). Em primeiro lugar, gênero é forma (de discurso, de enunciação). Mais que isso, o grande corolário desses termos é tema ou a significação acrescida da ideologia e da valoração, único fim de um enunciado vivo. Por isso, a forma de discurso, de enunciação. E não forma de texto, de enunciado.

O nome "formas de discurso social" esclarece, portanto, em primeiro lugar, que o gênero é uma forma não textual, mas discursiva. Não é, pois, nos limites de uma Linguística do Texto ou na recorrência de alguma materialidade textual - a exemplo do que faz, por exemplo, J. P. Bronckart (1999) -, que o Círculo de Bakhtin procura seu critério para definir os gêneros. Há vários outros elementos em jogo na produção concreta de um enunciado. Não se fala fora de um contexto histórico e de um contexto pragmático; não se fala sem que haja um sujeito falante e outro respondente (ainda que sua resposta possa não ser exteriorizada); não se fala sem que haja um meio de comunicação, seja a modalidade oral ou a escrita da língua etc. Tudo isso se conjuga no gênero, de modo que ele não pode ser apreendido apenas por regularidades textuais. Por isso, o gênero é uma forma de discurso. Cumpre ainda entender por que ele é uma forma de discurso social. Se o gênero emana de uma atividade em que a língua se faz necessária, então não é produto de um indivíduo, mas da interlocução entre vários indivíduos que, por estarem envolvidos numa mesma atividade, precisam se comunicar. Não pode o indivíduo, em isolado, criar um gênero ou alterar os que existem. Isso não significa, porém, que o indivíduo esteja condenado a apenas reproduzir os gêneros dados, sem poder agir sobre eles. Pelo contrário, Bakhtin (1997b, p. 301) adverte que a fala do enunciador adapta-se ao gênero, mas isso "sem que este [o enunciador] renuncie à sua individualidade e à sua subjetividade". Isso significa que um espaço fica resguardado para o falante manipular o gênero e mesmo transformá-lo (desde que essa transformação conte com o aval dos que utilizam o gênero). O gênero é, pois, submisso à ação humana, construído pela atividade do homem e na atividade do homem -, mas não do homem individual, isolado, e sim do homem em sociedade. Uma vez construído, o gênero limita as possibilidades de escolha do enunciador para a composição do enunciado, e o intuito dele passa a se realizar, fundamentalmente, na escolha de um dos gêneros dados para compor seus enunciados.

O querer-dizer do locutor se realiza acima de tudo na escolha de um gênero do discurso. Essa escolha é determinada em função da especificidade de uma dada esfera da comunicação verbal, das necessidades de uma temática (do objeto do sentido), do conjunto constituído dos parceiros, etc. (idem, ibidem, p. 301, grifo nosso)

É em função das requisições que as esferas da comunicação verbal fazem aos homens, bem como das motivações pessoais desses homens, que se realiza a escolha do gênero. Nota-se, pois, que essa escolha não é completamente livre. O exercício da subjetividade do enunciador, porém, não se restringe a ela. Feita a escolha, a produção do enunciado ainda pode transgredir, até certo ponto (ponto esse que varia de um gênero para outro), o padrão do gênero, e, conforme essa transgressão seja socialmente admitida, o gênero pode se alterar ou mesmo um novo gênero pode se criar do antigo. Assim, embora, por um 
lado, o gênero tenha um caráter normativo e submeta a fala a certa adequação, por outro, são os interlocutores que criam e moldam os gêneros em suas atividades.

\section{Alguns apontamentos sobre a psicologia de Leontiev}

A psicologia soviética teve seu auge com a obra de Vigotski, autor responsável por um grande salto no entendimento de certos problemas da psicologia e profundamente influente no mundo todo. Ele veio, no entanto, a falecer ainda jovem, e sua obra, que vinha dando sinais de grande riqueza, restou interrompida. Quem deu continuidade a ela foram alguns de seus colaboradores, também pesquisadores de prestígio. Entre eles, um dos de maior destaque foi Leontiev, cujo trabalho, ainda que com algumas discordâncias, pode ser visto como uma continuação da obra de Vigotski (DUARTE, 2004, p. 45).

A preocupação fundamental dos dois foi o desenvolvimento do psiquismo. Vigotski (1991; 1998) tratou do tema observando, principalmente, as fases desse desenvolvimento no homem, da criança ao adulto. Leontiev, por sua vez, observou, em seu mais famoso trabalho, esse desenvolvimento por outro ângulo, buscando reconstituir a gênese histórica do psiquismo tipicamente humano. O desenvolvimento que ele observa, então, não é da criança ao adulto, mas da pré-história do homem ao homem moderno.

Os estudos dos dois psicólogos russos comungam da certeza de que o psiquismo do homem é qualitativamente diferente do psiquismo animal. Essa afirmação é de Vigotski (1991, p.69), e Leontiev a herda e faz dela uma de suas principais teses. Para que possamos compreender seu pensamento, portanto, é necessário entender a distinção entre o psiquismo humano e o animal, ou seja, entender o que nos torna seres, de fato, humanos, distintos dos outros animais. Essa distinção, para Leontiev, assenta-se no trabalho (ideia herdada, dessa vez, de K. Marx e F. Engels). Segundo Leontiev, o homem distingue-se dos animais porque, ao contrário deles, não age no sentido de lograr a satisfação das suas necessidades biológicas, mas de produzir os meios para a satisfação dessas necessidades. A produção dos meios que permitam ao homem satisfazer suas necessidades é, no dizer de Marx \& Engels (1999, p.39), "o primeiro ato histórico", no sentido de que inicia a história humana e encerra sua pré-história. Esse ato histórico é "uma condição fundamental de toda a história, que ainda hoje, como há milhares de anos, deve ser cumprido todos os dias e todas as horas, simplesmente para manter os homens vivos" (idem, ibidem). Aceitando essa afirmação, Leontiev diz (1978, p. 74):

O trabalho é antes de mais nada caracterizado por dois elementos interdependentes. Um deles é o uso e o fabrico de instrumentos. [...] O segundo é que o trabalho se efetua em condições de atividade comum coletiva, de modo que o homem, no seio deste processo, não entra apenas numa relação determinada com a natureza, mas com outros homens, membros de uma dada sociedade. É apenas por intermédio desta relação a outros homens que o homem se encontra em relação com a natureza.

Dessas duas características do trabalho é que advém o que há de especificamente humano em nosso psiquismo. Muito se pode dizer a partir daí, mas, devido aos inevitáveis limites de espaço em um artigo, restringiremos nossas reflexões às implicações do uso de instrumentos para o desenvolvimento ontogênico da espécie humana e ao caráter coletivo do trabalho e sua relação com o surgimento da fala. Principiemos por este segundo ponto. 
O trabalho é, como foi dito, coletivo. Para seu bom funcionamento, é preciso, pois, que a coletividade consiga se organizar de modo que cada indivíduo desempenhe sua função a contento, para que o todo seja bem-sucedido em sua atividade. Isso torna a comunicação necessária e, por isso, segundo Leontiev (ibidem, p.86), a língua tem sua gênese na atividade coletiva do trabalho, que coloca os homens forçosamente em relação uns com os outros. A função comunicativa tende, com o tempo, a separar-se da produtiva e a abstrair-se dos objetos que reflete, passando a existir sob a forma de pensamento. Ela passa, então, a cumprir também o papel de veículo da consciência humana, permitindo ao homem realizar sua forma própria de pensar, que Vigotski chamou de "pensamento verbal".

Além da comunicação, o trabalho exige do homem a fabricação e a manipulação de instrumentos. A primeira reflexão importante que Leontiev faz sobre isso diz respeito ao fato de o instrumento refletir as características da atividade que realiza. Ele é o produto de uma experiência de trabalho, ou, para ser mais exato, de uma experiência social de trabalho, já que o trabalho é social. A atividade humana que se realiza com um instrumento cristaliza-se nele. Tomemos o machado como exemplo. Seu uso é o de cortar madeira, e sua forma não poderia ser outra que não um cabo e uma lâmina, de modo a possibilitar o trabalho que com ele se quer realizar. Assim, nas propriedades físicas do machado, está inscrita certa experiência de trabalho: a lâmina, evolução da pedra lascada; o cabo, que facilita o trabalho, e cuja invenção representa um salto qualitativo em relação ao uso de pedras afiadas; o comprimento do cabo, que forma uma alavanca capaz de ampliar a força do homem etc. Tudo isso é produto da experiência de séculos da humanidade em cortar madeira, fixada no instrumento. Além da própria atividade, fixa-se no instrumento também o emprego que ele tem no seu uso. Segundo Leontiev (ibidem, p. 82):

O instrumento não é apenas um objeto de forma particular, de propriedades físicas determinadas; é também um objeto social, isto é, tendo um certo modo de emprego, elaborado socialmente no decurso do trabalho coletivo atribuído a ele. [...] Razão por que dispor de um instrumento não significa simplesmente possuí-lo, mas dominar o meio de ação de que ele é o objeto material de realização.

Não basta ter o instrumento em mãos, é preciso também ter em mente o emprego do instrumento. Esse emprego é fixado no próprio instrumento, na sua forma física. Subjacente a ele, portanto, está o esquema mental de sua utilização, que é interiorizado por quem o manipula. $\mathrm{O}$ homem precisa interiorizar esses traços fixados no produto de seu trabalho, para assimilá-lo. É o que ocorre com toda criança quando ela vai aprender a lidar com os objetos do mundo humano. Ela precisa se apropriar do esquema mental subjacente aos objetos que a rodeiam para deles se valer, e é evidente que ela não faz isso sozinha. Toda utilização de um instrumento é acompanhada de algum contato social. A criança aprende a lidar com, por exemplo, um copo conforme o pai a ensina. Ela logo se apropria do esquema de uso do copo, abandonando seus reflexos incondicionais ao beber água, como os movimentos de sucção, e passando a comportar-se de outro modo, condizente com o uso do copo no ato de beber (idem, ibidem, p.179). Interiorizar o esquema de uso de um copo modifica as funções motoras da criança, que deixa de contrair as narinas, esticar os lábios para adiante e tentar sugar a água, e passa a abrir as narinas, projetar o lábio inferior e abaixar a língua, para que a água escorra do copo inclinado para sua boca. Esse tipo de reorganização dos reflexos incondicionais se dá em todo contato do homem com os produtos do trabalho humano. É assim que a música modifica a audição do homem, o emprego de equipamentos de trabalho modifica suas habilidades motoras, a língua modifica suas faculdades comunicativas 
etc. Os produtos da atividade do homem alteram o homem, e ele transmite essa alteração a seus descendentes ao ensiná-los a se comportar no mundo humano, que é o mundo transformado pelo trabalho.

Essa última constatação leva-nos a uma importante consideração de Leontiev sobre o desenvolvimento ontogênico humano. Para ele, o desenvolvimento de uma espécie se deve à fixação de suas aquisições evolutivas e à transmissão delas. Nos animais, ambas as coisas se dão pela hereditariedade biológica. O homem, porém, a partir de um estágio de sua evolução, devido às potencialidades que seu cérebro passou a ter, tornou-se capaz de fixar aquisições de outro modo que não depende de novas evoluções biológicas. Essa maneira de fixar aquisições é chamada por Leontiev de "exterior", por não estar inscrita "sob a forma de particularidades morfológicas, de variações fixadas pela hereditariedade" (idem, ibidem, p.164). Essa fixação exterior das aquisições do desenvolvimento humano é a que descrevemos acima, feita nos produtos do trabalho do homem. Ela tornou possível ao homem transmitir às gerações posteriores suas aquisições de uma forma não biológica, mas sócio-histórica. $\mathrm{O}$ que é especificamente humano funda-se, portanto, na historicidade: é apenas ao apropriar-se das aquisições históricas do gênero humano que o homem se humaniza. Essa apropriação ocorre quando ele trava contato com os produtos da atividade humana, e interioriza as aquisições que nesses produtos se imprimiram. A interiorização é o meio como o homem adentra o gênero humano, o que a torna obrigatória no desenvolvimento da espécie humana (idem, ibidem, p. 188).

\section{Algumas relações da psicologia de Leontiev com a noção de gêneros do discurso}

Vimos, nos trechos anteriores deste trabalho, o olhar do Círculo de Bakhtin sobre os gêneros do discurso e algumas considerações de Leontiev sobre o desenvolvimento histórico do psiquismo humano. Como dissemos, esses autores têm, como referência comum, os textos de Marx e Engels. A influência do pensamento de tradição marxista é mais forte e visível nos trabalhos de Leontiev do que nos do Círculo de Bakhtin, devido ao Círculo buscar fontes mais variadas, que incluíam, desde o marxismo até o neokantismo, a fenomenologia e a filosofia da vida. Essa variedade de referências justifica os muitos estudos feitos sobre a paternidade de cada obra do Círculo, ou sobre a filiação teórica de cada membro. Não pretendemos reduzir o debate travado no interior do Círculo de Bakhtin a um consenso em torno do marxismo. Ocorre, porém, que o reconhecimento de que o marxismo é uma das fontes de que o Círculo se vale já basta para podermos aproximá-lo dos trabalhos de Leontiev. Essa aproximação não é, portanto, eclética ou absurda. Há, inclusive, autores renomados que já a fazem, entre os quais se pode citar, por exemplo, Bronckart (1999) e seus companheiros do Interacionismo Sociodiscursivo. $O$ fato de pesquisadores respeitados aproximarem do Círculo de Bakhtin os estudos de Leontiev (e mesmo os de Vigotski, espécie de pai da obra de Leontiev) basta para que se veja que tal aproximação é totalmente plausível. Entraremos nela apontando a forte concordância entre a hipótese de Leontiev sobre o surgimento da língua e o conceito de gêneros do discurso do Círculo de Bakhtin.

Bakhtin/Voloshinov (1999, p. 43) diz que "as formas da comunicação verbal" (ou seja, os gêneros do discurso) "são inteiramente determinadas pelas relações de produção e pela estrutura sociopolítica". As relações de produção a que ele se refere aqui são as da tradição marxista: as relações de produção da vida material. É dessas relações que advêm os gêneros do discurso em última análise, e isso porque os gêneros derivam de alguma atividade humana em que se exija interlocução, e essas atividades surgem em estreita relação com o modo de produção de uma sociedade, segundo nos diz o próprio Bakhtin/Voloshinov (ibidem, 
p.42): "as relações de produção e a estrutura sociopolítica que delas diretamente deriva determinam todos os contatos verbais possíveis entre indivíduos, todas as formas e os meios de comunicação verbal". Essas relações de produção condicionam, portanto, o surgimento de todos os gêneros do discurso. É interessante ainda recordar que, para o Círculo de Bakhtin, o centro organizador da língua não é o seu sistema, mas o diálogo, a interlocução. Em sua famosa crítica ao que chamou de "objetivismo abstrato", Bakhtin/Voloshinov esclarece que "a consciência subjetiva do locutor não se utiliza da língua como um sistema de formas normativas" (ibidem, p.92), e sim que esse sistema é apenas o modo como a consciência individual, situada num recorte histórico, percebe a língua. Para ele, é, na verdade, pela interlocução que as formas da língua se estabilizam (1997b, p.285) e constroem o sistema. E como toda interlocução se faz com a referência de um gênero, pode-se dizer que o próprio sistema da língua sofre condicionamentos, em alguma medida, do modo de produção da vida material. As posições do Círculo de Bakhtin e de Leontiev são, portanto, conciliáveis, já que, para este último, a língua é um construto social, oriundo da atividade de trabalho, na qual se faz a produção da vida material de uma sociedade.

Há quem julgue que essa posição seja determinista. Bronckart (1999, p. 143), por exemplo, julga: "A concepção bakhtiniana [...] parece implicar uma relação de dependência quase mecânica entre formas de atividades e gêneros de discurso, forma de dependência que contestamos" (nota de rodapé). Em Bakhtin/Voloshinov (1999, p. 39), porém, já se advertia contra esse equívoco:

Sempre que se coloca a questão de saber como a infraestrutura determina a ideologia, encontramos a seguinte resposta que, embora justa, mostra-se por demais genérica e por isso ambígua: "a causalidade". Se for necessário entender por causalidade a mecanicista [...], então uma tal resposta se revela radicalmente mentirosa e contraditória com os próprios fundamentos do materialismo dialético.

Não se trata de determinismo, mas de reconhecimento do fato de que os contextos materiais em que toda ação verbal pode ocorrer decorrem da forma como se faz a produção da vida material em uma sociedade. Na produção do Círculo de Bakhtin, não há a crença em uma ideologia que apenas se ajusta aos movimentos da infraestrutura social (como certa vulgarização do marxismo se compraz em afirmar), mas sim a afirmação de que, entre as duas instâncias, há uma "relação recíproca" (idem, ibidem, p. 41), o que desautoriza interpretações deterministas ou mecanicistas dos trabalhos do Círculo. A compreensão adequada da relação entre infraestrutura e ideologia, tal como eles a concebem, é não mecanicista ou determinista, mas dialética. Dizemos isso em conformidade com o que está exposto no excerto que citamos acima: nele, afirma-se como é a causalidade dialética que explica a relação entre a ideologia e a infraestrutura. E já que a ideologia é, para o Círculo, necessariamente semiotizada - de acordo com o que se vê em textos como os de Bakhtin/Voloshinov (1999) e Bakhtin (2001) -, a causalidade dialética oferece a chave para se interpretar a produção dos enunciados e, como não pode deixar de ser, dos gêneros. Se todo enunciado atende a condições da situação de produção da vida material, como dissemos, e se todo enunciado realiza um gênero, é porque todo uso da língua atende a uma relação dialética com o contexto material em que se produz. E, embora isso possa ser entendido como uma aplicação do marxismo ao estudo da língua, nunca é demais lembrar que certos marxistas de então simplificavam ao extremo a questão, e dando a entender que a ideologia simplesmente se adaptava à infraestrutura social. A isso, Bakhtin/Voloshinov (ibidem, p. 39-40) responde: 


\begin{abstract}
Antes de mais nada, é impossível estabelecer o sentido de uma dada transformação ideológica no contexto da ideologia correspondente, considerando que toda esfera ideológica se apresenta como um conjunto único e indivisível cujos elementos, sem exceção, reagem a uma transformação da infraestrutura. Apenas sob esta condição a análise desembocará, não na convergência superficial de dois fenômenos fortuitos e situados em planos diferentes, mas num processo de evolução social realmente dialético, que procede da infraestrutura e vai tomar forma nas superestruturas.
\end{abstract}

Veja-se que o Círculo está tomando a dialética como forma de se compreender a relação entre a produção dos enunciados e o contexto material. É o que está expresso não só nos dois últimos trechos que citamos, mas também em passagens tais como esta, em que o Círculo trata dos condicionamentos socioeconômicos sobre a ideologia do cotidiano:

\begin{abstract}
Mas tudo isso [estudos de Pavlov e Loeb] é muito pouco para explicar o comportamento humano. Especialmente aqueles conflitos do comportamento verbalizado, com os quais o freudismo nos faz deparar, para serem compreendidos necessitam, antes de tudo, de uma consideração rigorosa e plurilateral dos fatores socioeconômicos. Só com o auxílio dos métodos flexíveis do materialismo dialético nos será possível lançar luz sobre esses conflitos. (BAKHTIN, 2001, p. 84).
\end{abstract}

Essas explanações são necessárias, principalmente, devido ao emprego, em nosso artigo, da palavra dialética. Se em referência à obra de Leontiev ela não causa susto algum, para alguns leitores do Círculo de Bakhtin, ela pode causar estranheza e exige algumas explicações. Não se podem aproximar os autores do Círculo do pensamento de Leontiev de maneira irresponsável, dando a entender que todos os membros do Círculo eram marxistas. Há, ao contrário, tantos contraditórios entre os membros do Círculo quanto entre os analistas que sobre ele refletiram. Mas, desde que conscientes de que o Círculo de Bakhtin não se reduz apenas ao marxismo, cremos ser possível traçar uma leitura da obra do Círculo que se apoie em conceitos tradicionalmente trabalhados pelos marxistas. Afinal, se não se pode reduzir os trabalhos do Círculo à influência do marxismo, tampouco se poderá apagar essa influência deles. Isso está demonstrado, ao que nos parece, pelos três últimos trechos que citamos.

Há também, claro, trechos de obras dos autores do Círculo de Bakhtin em que se polemiza com a dialética. O mais famoso deve ser o caso do texto "Apontamentos de 197071". Nessa obra, a única referência direta à dialética está no trecho em que se diz: "No diálogo, tiram-se-lhe as vozes (separação das vozes), a entonação (emotivo-personalizada), as palavras vivas e as réplicas, extraem-se dele noções abstratas e raciocínios. Põe-se tudo numa consciência abstrata e obtém-se a dialética." (BAKHTIN, 1997a, p. 388).

Vários são os que citam este trecho para afirmar a polêmica do Círculo com a dialética hegeliana, como fez, por exemplo, A. Ponzio (2008, p.186-8). Essa é uma leitura possível, mas que não desautoriza entender-se o gênero em sua relação dialética com a atividade de que ele emana. Estamos asseverando o caráter dialético dessa relação, em específico - ou seja, a relação dialética entre os condicionantes socioeconômicos dos enunciados e os enunciados mesmos, relação essa exposta claramente nos trechos acima e em nada negada no excerto dos "Apontamentos de 1970-71", que trata das relações de um enunciado com outros enunciados.

Antes de prosseguirmos nesse raciocínio sobre a aplicação da dialética ao estudo dos gêneros de discurso, é necessário fazer algumas considerações a respeito do caráter Disponível em: http://seer.fclar.unesp.br/casa 
sócio-histórico que os autores do Círculo de Bakhtin conferem à língua. Como se sabe, para eles todo enunciado sofre condicionamentos da situação de sua produção, e o fato de afirmarem que o gênero brota de uma atividade humana em que se exija o uso da língua testemunha a importância que eles conferem à situação de produção dos enunciados. Ocorre, porém, que não falamos apenas do contexto imediato de produção, mas também do contexto histórico. Bakhtin/Voloshinov (ibidem, p.103) mesmo afirma que "a concretização da palavra só é possível com a inclusão dessa palavra no contexto histórico real de sua realização" (grifo nosso). Bakhtin (1997b, p. 313, grifo nosso) afirma sobre o gênero:

\begin{abstract}
A época, o meio social, o micromundo [...] que vê o homem crescer e viver, sempre possui seus enunciados que servem de norma, dão o tom; são obras científicas, literárias, ideológicas, nas quais as pessoas se apoiam e às quais se referem, que são citadas, imitadas, servem de inspiração. Toda época, em cada uma das esferas da vida e da realidade, tem tradições acatadas que se expressam e se preservam sob o invólucro das palavras, das obras, dos enunciados, das locuções, etc. Há sempre certo número de ideias diretrizes que emanam dos "luminares" da época, certo número de objetivos que se perseguem, certo número de palavras de ordem, etc.
\end{abstract}

Como quisemos destacar com nossos grifos, os gêneros não se determinam apenas pelas atividades de uma esfera da vida às quais se ligam, mas também pela época - ou seja, pelo momento histórico - em que existem. Nós acrescentaríamos que as próprias atividades das quais os gêneros emanam são características de uma época, por serem, elas mesmas, históricas. Todas as atividades humanas, e com isso todas as situações em que o contato verbal se dá, estão em relação com a produção da vida material, o que torna os gêneros que emanam dessas atividades humanas tão históricos quanto elas próprias.

Se entendermos a historicidade humana como Leontiev propõe, teremos, ao admitir que o gênero é histórico, que concluir mais do que os fatos de ele se alterar com o tempo e de ter sido concebido pelas gerações anteriores. Assim como ocorre com qualquer produto do trabalho do homem, o gênero produzido pela atividade humana tem gravado em si as aquisições do período histórico em que emerge, e seu trânsito pela história faz com que ele prossiga agregando em si mais e mais traços da atividade humana de que toma parte. Quanto mais os homens trabalham com o gênero, mais o alteram, e ele, quanto mais alterado está, mais da história humana guarda em si. Lembremos que, para Leontiev, a interiorização é um mecanismo fundamental para o desenvolvimento ontogênico humano. Isso é válido para os gêneros do discurso. Quando alguém interioriza um gênero, interioriza junto os traços históricos fixados nele. Esses conceitos de Leontiev, extraídos da mesma matriz marxista presente no Círculo de Bakhtin, lançam luz sobre a insistência do Círculo em considerar o enunciado como objeto não neutro, e o signo como ente que não só reflete a realidade, mas que também a refrata. Por refratar entende-se que o signo guarda marcas da atividade humana que incorporamos ao travar contato com ele e que modificamos quando agimos sobre ele, usando-o em nossos enunciados. E como o signo, quando tomado não em abstrato, mas na sua concretude, é um "eco do gênero em sua totalidade" (idem, ibidem, p. 312), é possível afirmar o mesmo do gênero. O gênero, por emanar do trabalho humano, impregna-se de condicionamentos históricos e, por isso, não pode ser neutro.

Estamos agora em condições de retomar a questão que deixamos em suspenso, sobre a dialética aplicada ao estudo dos gêneros do discurso. Para isso, é útil o seguinte comentário sobre o método dialético: 
[...] observando as coisas detidamente, verificamos que os dois polos de uma antítese, o positivo e o negativo, são tão inseparáveis quanto antitéticos um do outro, e que, apesar de todo o seu antagonismo, se penetram reciprocamente; e vemos que a causa e o efeito são representações que somente regem, como tais, em sua aplicação ao caso concreto, mas que, examinando o caso concreto em sua concatenação com a imagem total do universo, se juntam e se diluem na ideia de uma trama universal de ações e reações, em que as causas e os efeitos mudam constantemente e em que o que agora ou aqui é efeito adquire em seguida ou ali o caráter de causa, e vice-versa. (MARX; ENGELS, 1999, p. 316)

Nessa explicação de Engels, importa-nos particularmente a consideração sobre o modo como a causa pode se tornar, no momento seguinte, efeito, e vice-versa. Esse detalhe sobre a dialética (conforme Bakhtin/Voloshinov) não se concilia com determinismo ou mecanicismo de nenhuma natureza. Para vermos isso nos gêneros do discurso, lembremo-nos de que o gênero, tal como o descrevemos, é a estabilização de formas discursivas julgadas necessárias ou pertinentes à atividade em que o gênero se engaja - ou seja, os enunciados produzidos em uma atividade não simplesmente nascem dela, mas atuam nela, engajam-se nela. Tomemos um exemplo. Os juízes, para realizar suas ações na atividade de que participam, precisam recorrer à língua; certos recursos à língua são reiterados, conforme tal atividade os exija ou os privilegie. Descrever as coisas, assim, deixa a sensação de que temos dois polos separados: de um lado, a atividade, e de outro, os enunciados produzidos a propósito desta atividade. Mas produzir os enunciados é realizar a atividade, ou uma parte dela, ao menos. A produção de um enunciado é, concretamente, parte da ação do juiz, e só se separa dela por trabalho do intelecto humano e com motivações metodológicas. Isso demonstra um fato importante sobre os gêneros: se, por um lado, a modificação da atividade implica uma nova situação de comunicação e, portanto, parâmetros novos para a formação dos enunciados, por outro lado, o modo como os enunciados são produzidos também implica mudanças na atividade. Afinal, se as formas discursivas dos enunciados produzidos por um juiz são necessárias ou desejáveis a uma atividade qualquer, é porque elas realizam uma função necessária ou desejável nessa atividade. Caso se produzissem enunciados com outras formas discursivas no lugar dessas (dentro, claro, do possível, nas condições em que a interlocução se dá), parece óbvio que a atividade sofreria modificações, pois essas novas formas discursivas realizariam ou novas funções na atividade, ou as mesmas funções, mas de novas maneiras. Por isso, não se pode falar o que se quer, como se quer e onde se quer: a atividade em que a fala se insere limita essas possibilidades, pois toda atividade sai alterada pela fala, e daí decorre que os envolvidos em uma atividade filtrem as falas convenientes e/ou indispensáveis entre as possíveis. Dizer o contrário é assumir a via de mão única, crendo que a situação material determina (e não condiciona) os enunciados e adotando a causalidade mecanicista que Bakhtin/Voloshinov recusou, e que certo marxismo, pouco baseado em Marx, assumiu.

Segue, portanto, que não apenas as atividades humanas determinam as características do gênero, mas as características do gênero determinam a forma como as atividades humanas em que ele se engaja ocorrem. O gênero emerge justamente porque certos procedimentos no uso da língua, em detrimento de outros, são necessários ou desejáveis à realização de alguma atividade humana - e isso demonstra que o gênero influencia o modo como essas atividades se realizam. É possível, como foi dito, que o falante introduza modificações num gênero ao usá-lo, desde que as modificações sejam socialmente validadas. Logicamente, modificar-se-á também, com isso, em alguma medida, a atividade em que o 
gênero é engajado. Há, portanto, uma relação dialética entre o gênero e a atividade da qual ele emana, pois, embora seja a atividade que faça o gênero florescer, uma vez florescido ele poderá se alterar e, assim, levar a atividade também a alterar-se. Ocorrendo isso, a atividade passará a impor novos condicionamentos ao gênero que, por isso, tornará a se modificar, mudando a forma como a atividade se dá etc. A atividade, portanto, da qual o gênero emana o condiciona, mas é também por ele condicionada. Assim, a causa torna-se, no momento seguinte, o efeito, e o efeito, a causa, num claro exemplo de relação dialética, tal como Engels a expôs.

Dissemos que, assumindo as ideias de Leontiev, teríamos de admitir que certos traços da atividade humana em que o gênero toma parte se fixam nele, impedindo-o de ser neutro. Esses traços variam, evidentemente, de um gênero para outro. É invariável, porém, que esses traços, a exemplo do cabo e da lâmina do machado que citamos no item anterior, serão frutos de uma experiência social de uso da língua na atividade em que o gênero se engaja. É a atividade coletiva do homem que cria o gênero e o molda e, sendo assim, quando alguém interioriza um gênero, está interiorizando a experiência social humana nele acumulada. Esse raciocínio, originalmente de Leontiev e aqui importado para a noção de gêneros do discurso, traz implicações ao dialogismo. Quando se pensa que a existência de uma comunicação exige interlocutores capazes de dirigir seus pensamentos de forma comum, tem-se imediatamente a certeza de que só lhes será possível fazê-lo caso disponham de um mecanismo para tanto que ambos dominem igualmente (ou quase). A língua, vista dessa forma, tem que ser supraindividual e, sendo, precisa repousar na qualidade de ente social. É conhecida a veemente recusa dos autores do Círculo de Bakhtin a um conceito de língua (por eles chamado de "subjetivismo idealista") que a entende como simples tradutora do universo idiossincrático do falante. Essa posição foi considerada por muitos como uma opção pelo social, em detrimento do individual - e daí para a acusação de determinismo, o caminho é curto. Parece-nos que o entendimento adequado dessa posição não seja este, mas aquele que, parafraseando Engels, vê os polos do social e do individual como tão inseparáveis quanto antitéticos. Tomado em sua concretude, o social não é formado de nada mais que indivíduos, e isso nos obriga a assumir que, ao se levar o social em conta, deve-se levar o individual também e vice-versa. Individual e social são dois polos antitéticos, mas compõem uma totalidade - a unidade dos opostos. O individual está presente no social, já que a sociedade não existe sem indivíduos que a componham. No que tange à língua, isso também é válido, pois o compartilhamento de formas comunicativas pelo coletivo exige seres humanos singulares recorrendo, em cada enunciado, a formas consensuais de comunicação. $\mathrm{O}$ social, por sua vez, está também presente no individual, pois, se cada enunciado recorre a formas consensuais, então em cada enunciado singular uma ocorrência social se manifesta. $\mathrm{O}$ dialogismo, assim, é mais do que simples intersubjetividade. Ainda que seja isso também, é a presença do outro no discurso do eu, é a alteridade como elemento constitutivo do funcionamento da língua, o social e o individual em interação dialética. Por considerar desse modo as reflexões do Círculo de Bakhtin, é que se pode afirmar, como Faïta (1997, p. 165), que "cada um desses enunciados [que circulam na sociedade] é a realização individual do estilo geral ao qual ele pertence".

A expressão maior da interação entre individual e social nos autores do Círculo de Bakhtin está em suas considerações sobre a psicologia. Tendo em mente que, para eles, a atividade psíquica humana exige a presença de algum material semiótico, e que não há diferença qualitativa entre pensamento e expressão (BAKHTIN / VOLOSHINOV, 1999, p. 51-2), Bakhtin/Voloshinov afirma que "O signo ideológico tem vida na medida em que ele se realiza no psiquismo e, reciprocamente, a realização psíquica vive do suporte 
ideológico. A atividade psíquica é uma passagem do interior para o exterior; para o signo ideológico, o processo é inverso" (op.cit., p.64, grifo nosso). Todo o conteúdo do psiquismo tipicamente humano repousa na qualidade de signo, e esses signos só podem ser obtidos no contato com os outros indivíduos, e só podem permanecer vivos na medida em que estejam inseridos no sistema social que os anima, ainda que se destinem à introspecção. A própria introspecção, assim, é expressão potencial. A existência do signo com vistas à comunicação exige, por sua vez, que haja interiorização das formas linguísticas por um amplo conjunto de indivíduos. Assim, tanto o signo interior só pode existir na medida em que se insere na ideologia, quanto o signo ideológico só é possível conforme esteja interiorizado pelos falantes. Ou seja, social e individual, na língua, são polos tão antitéticos quanto inseparáveis. Bakhtin/Voloshinov mesmo diz que, entre o psicológico e o ideológico (leia-se, o individual e o social), há uma "interação dialética indissolúvel" (ibidem, p.65), o que desautoriza leituras de sua obra que preguem uma primazia do social sobre o individual.

Há, nessas reflexões, uma forte concordância entre o Círculo de Bakhtin e Leontiev. Vejamos um excerto desse último (1978, p. 94):

A significação é a generalização da realidade que é cristalizada e fixada num valor sensível, ordinariamente a palavra ou a locução. É a forma ideal, espiritual da cristalização da experiência e da prática sociais da humanidade. A sua esfera das representações de uma sociedade, a sua ciência, a sua língua existem enquanto sistemas de significações correspondentes. A significação pertence, portanto, antes de mais, ao mundo dos fenômenos objetivamente históricos.

Se a língua cristaliza a experiência humana, é porque é capaz de refratá-la. Essa refração, como dissemos, pode ser esclarecida pelas ideias de Leontiev acerca de como se fixam as características do trabalho humano naquilo que esse trabalho produz. Tudo o que é linguístico, os gêneros inclusive, fixa em si caracteres do trabalho social humano que o gera. Se a língua é produto de um trabalho social, e se isso deixa traços nela, então o falante que a interiorize, interiorizará uma experiência da sua coletividade que nela esteja objetivada. A partir daí, afirma Leontiev (ibidem, p. 98):

[...] se bem que o sentido ("sentido pessoal") e a significação pareçam, na introspecção, fundidos na consciência, devemos distinguir estes dois conceitos. Eles estão intrinsecamente ligados um ao outro, mas apenas por uma relação inversa da assinalada precedentemente; ou seja, é o sentido que se exprime nas significações (como o motivo nos fins) e não a significação no sentido.

Aqui, Leontiev distingue o sentido pessoal do que ele chama de significação, que nada mais é do que o sentido coletivo, fixado nas palavras. Segundo ele, o sentido pessoal busca se exprimir na significação objetiva, de modo a fazer-se compreensível aos demais. Essas noções de Leontiev demarcam diferenças entre o modo como os sentidos habitam o universo interior do falante (o que ele chama de "sentido pessoal") e o modo como eles se fixam na ideologia (o que ele chamou de "significação"). Comentamos como, para os autores do Círculo de Bakhtin, esses dois planos de existência do signo (o psicológico e o ideológico) se sobrepõem, não havendo entre eles distinções qualitativas. Aqui, há certa diferenciação entre a concepção dos autores que estamos aproximando: Leontiev diferencia o sentido 
pessoal e a significação social de forma definitiva, enquanto, para os autores do Círculo de Bakhtin,

[...] não há fronteira a priori entre o psiquismo e a ideologia. Há apenas uma diferença de grau: no estágio do desenvolvimento interior, o elemento ideológico, ainda não exteriorizado sob a forma de material ideológico, é apenas um elemento confuso. Ele não pode aperfeiçoar-se, diferenciar-se, afirmar-se a não ser no processo de expressão ideológica (BAKHTIN/VOLOSHINOV, 1999, p. 57. grifo nosso).

Cumpre, porém, esclarecer que a língua não era o objeto de estudo de Leontiev, e que, por isso, ele podia se dar a certas simplificações ao tratar da matéria. Essa diferenciação entre sentido pessoal e significação, na obra que consultamos (LEONTIEV, 1978), é feita rapidamente, sem maiores reflexões. Apesar da diferença entre essa sua concepção e a dos autores do Círculo de Bakhtin, parece-nos possível, adotando a visão bakhtiniana do signo, concordar com Leontiev em que a individualidade precisa submeter-se a certas coerções, próprias da expressão, para fazer-se compreensível aos demais. É exatamente essa ideia que está subjacente à última citação que fizemos de Bakhtin/Voloshinov, na qual se afirma que o elemento psicológico é ainda confuso, necessitando, para afirmar-se, de sua expressão ideológica - ou seja, necessitando tornar-se signo para os outros, ao menos potencialmente. Como esse raciocínio demonstra, não é impossível, adotando a postura bakhtiniana (frise-se essa opção), conciliar as noções de signo psicológico e signo ideológico, do Círculo de Bakhtin, e de sentido pessoal e significação, de Leontiev. Sendo assim, e admitindo-se, por um lado, que a individualidade precisa, para fazer-se compreensível, adaptar-se a certas condições próprias da expressão, e, por outro, que a língua ganha seus traços ao ser submetida ao trabalho social humano - admitindo-se essas duas afirmações de Leontiev -, tem-se uma referência para interpretar a noção de refração a que se refere o Círculo de Bakhtin. Sobre a refração, Bakhtin/Voloshinov (1999, p.46) diz: "o ser, refletido no signo, não apenas nele se reflete, mas também se refrata. O que é que determina essa refração do ser no signo ideológico? O confronto de interesses sociais nos limites de uma só e mesma comunidade semiótica, ou seja: a luta de classes". É nesses signos - e gêneros, já que só dentro deles os signos podem fazer sentido, ser modificados e mesmo surgir - que guardam traços do conflito entre as classes sociais no seio da comunidade em que circulam, que o homem tem o suporte para traduzir sua subjetividade em termos compreensíveis aos demais. Mais que isso, a subjetividade do homem só é possível conforme ele manipule os signos ideológicos em seu universo interior, de modo que sua subjetividade mesma é, em certa medida, social, e sofre os mesmos condicionamentos que o signo ideológico.

Essa relação entre o signo interior e o signo ideológico (ou seja, entre a significação social e a subjetiva, o que não é mais que uma faceta linguística da dicotomia entre social e individual) perpassa, é claro, não apenas a produção, como a compreensão dos enunciados. E isso por muitas razões, mas principalmente porque a compreensão, para os autores do Círculo de Bakhtin, tem que ser ativa, produtiva, ou, como em Bakhtin (1997a, p. 386), uma "resposta a uma pergunta. O que não responde pergunta nenhuma carece de sentido". Ou seja, a compreensão é a produção de um enunciado responsivo, e se a compreensão é produção, ela está sob os mesmos condicionamentos sociais que todo enunciado que se produz. As apreciações valorativas que se fixam no gênero tornam-se, pois, referência tanto para a produção como para a compreensão de enunciados, constrangendo, assim, até certo ponto, ambas as atividades, e servindo como referência para o enunciador se fazer compreender por seus enunciatários. Essas apreciações valorativas se objetivam no 
gênero, e podemos entender essa objetivação do modo proposto por Leontiev, que vimos comentando. As exigências do gênero devem se conjugar com os intentos do enunciador, de modo a compor o enunciado.

O oposto também é verdadeiro: se é preciso compor enunciados com referência a uma forma discursiva socialmente reconhecível, é lógico supor que se compreendem enunciados também com referência a essa forma - se não, por que o enunciador precisaria se adequar a ela? Se o gênero é impregnado com os traços da atividade que o gera, e se sua interiorização por parte dos falantes influencia no entendimento das trocas verbais, então os traços que o gênero guarda em si da atividade humana influenciarão na compreensão mútua dos componentes de um grupo social. Se o gênero não é neutro, não oferece um padrão neutro para a compreensão mútua. Ao contrário, o gênero guarda em si a lente da apreciação social (que, justamente por ser apreciação, não é neutra) sobre os enunciados particulares.

Como se vê, toda essa interpretação do conceito de gêneros do discurso como não neutro vem com o pressuposto de que ele serve ao propósito de realizar uma ação. Esse caráter, digamos, prático do gênero está subentendido nos escritos do Círculo de Bakhtin, na medida em que afirmam que o gênero emana de uma esfera de comunicação, e que interpretemos isso como sua inserção na atividade a propósito da qual o gênero se realiza (afinal, se o gênero é exigido em uma esfera de atividade humana, é porque nela desempenha algum papel). Entendendo-se essa emanação do gênero como uma exigência surgida no seio do processo de trabalho humano, temos uma perspectiva de gênero discursivo que nos autoriza a imaginar seu caráter instrumental. Perceba-se: não estamos afirmando que esse caráter esteja dito de nenhuma forma nos escritos do Círculo, mas sim que nele esse caráter pode ser inferido, que ele está implícito. Também não pretendemos, em nenhum momento, reduzir o gênero a esse seu caráter. Há muito mais riqueza e complexidade no trato dos gêneros do discurso do que apenas seu lado instrumental. Mas não nos parece fácil negar que o gênero tenha esse caráter também, e se assim for, esse caráter não poderá ser ignorado. Está subjacente também na afirmação de Leontiev, segundo a qual a língua emerge da necessidade de interlocução nas atividades sociais de trabalho, que há um imperativo prático no uso da língua. Consideramos que esse raciocínio de Leontiev é condizente com os gêneros, e que ele reforça nossa tese sobre como o gênero deve ser encarado. Leontiev (1978, p.96) afirma que o homem, em seu contato com a língua, "encontra um sistema de significações pronto, elaborado historicamente, e apropria-se dele tal como se apropria de um instrumento". E é da natureza do instrumento ser mediador para a realização de algum fim.

O instrumento não é apenas um objeto de forma particular, de propriedades físicas determinadas; é também um objeto social, isto é, tendo um certo modo de emprego, elaborado socialmente no decurso do trabalho coletivo atribuído a ele. [...] Razão por que dispor de um instrumento não significa simplesmente possuí-lo, mas dominar o meio de ação de que ele é o objeto material de realização. (idem, ibidem, p. 82)

O meio de ação de que o enunciador deve dispor ao usar a língua é a ele oferecido no gênero, materializado nos textos que emanam de uma dada esfera da comunicação verbal. Há, assim, lógica em se encarar o gênero como um instrumento, no sentido que Leontiev dá à expressão, e que é o sentido tradicional do marxismo. Não é uma proposta nova a de se encarar a língua como instrumento: já antes de Leontiev, Vigotski a havia feito. A adoção de um conceito de gênero (e não de língua) como instrumento é que é mais nova. Schneuwly (2004), mais recentemente, tornou a apresentar essa formulação, reforçando a ideia de que o gênero oferece orientação para a realização de algum objetivo. 
Vale notar que essa noção deve ser atravessada pela que vimos defendendo aqui, da não neutralidade do gênero. A orientação que o gênero fornece para a realização de alguma ação verbal - e o propósito mesmo da ação - atende sempre a interesses que guardam alguma relação com o modo de produção da vida material de uma sociedade, não podendo estar livre desses condicionantes, mas podendo sempre também condicioná-los.

\section{Considerações finais}

Como se viu, as aproximações entre a produção do Círculo de Bakhtin e a de Leontiev não é feita sem a necessidade de explicações, tergiversações, negociações. Isso porque, em primeiro lugar, a base comum entre Leontiev e o Círculo de Bakhtin - o marxismo - não é uma tradição intelectual homogênea. Dentro do marxismo há espaço para o contraditório, e houve, mesmo, muitas divergências entre os marxismos ao longo de todo o século XX. Daí a necessidade que sentimos, ao longo do texto, de distinguir o que se chama de "marxismo vulgar" do marxismo praticado por Leontiev e pelos membros do Círculo. A teoria do reflexo automático da infraestrutura na superestrutura não se sustenta no pensamento de Leontiev, e de modo algum se sustentará no pensamento dos autores do Círculo de Bakhtin. Em segundo lugar, as oposições dentro do próprio Círculo trazem dificuldades consideráveis à aproximação entre seus pensadores e Leontiev. Mas, mais ainda que as oposições dentro do Círculo, a dificuldade de se atribuir as ideias ali produzidas a uns membros ou a outros é, sem dúvida, o maior problema que se precisa enfrentar para fazer as tais aproximações. Devido a ele, uma leitura das ideias do Círculo mais próxima de Marx e Engels (ou de qualquer outra referência do Círculo tomada em isolado) suscitará desconfiança de reducionismo; e uma leitura que tente envolver a miríade de posições teóricas do Círculo deixará a impressão de ecletismo. A variedade de posições no Círculo de Bakhtin chega a autorizar leituras contrárias e, mesmo, contraditórias das obras, e isso, pode-se supor, porque as obras foram escritas por pessoas diferentes. Como as autorias corretas das obras é, hoje, um problema sem solução ${ }^{3}$, torna-se difícil traçar uma leitura homogênea das obras do Círculo (sempre alguém pode se basear numa obra de um período da produção do Círculo e ver-se contradito por uma de outro período, ou de outro suposto autor...). Para lidar com essa dificuldade, nossa opção foi a de, deliberadamente, ler a produção do Círculo com o olhar do marxismo e, com essa lente nos olhos, construir uma interpretação do conceito de gêneros de discurso. Não era nossa intenção "encontrar" a leitura certa dos textos do Círculo (tentativa que os autores do Círculo, certamente, não aprovariam), mas a de produzir, dialogicamente, a interpretação que, pelos motivos expostos, julgamos conveniente. Por último, o mais importante: é preciso estar atento às discordâncias (às vezes sutis, às vezes nem tanto) entre o Círculo de Bakhtin e Leontiev, para evitar erros conceituais.

O maior perigo da leitura que intentamos construir é o de reificar o gênero. Não é nossa intenção, de maneira alguma, tornar estático o que é dinâmico por natureza. Ao usar, porém, o léxico trazido da obra de Leontiev, podemos ter deixado essa impressão. Afirmar que os traços históricos "fixam-se" no gênero, "objetivam-se" nele e lá permanecem, que o gênero pode ser visto por seu caráter instrumental etc. - afirmar tudo isso - faz parecer que o gênero foi por nós encarado como produto e não como produção. De fato, o leitor atento deve ter notado que as coisas se passam mais ou menos assim nas considerações de Leontiev acerca da língua. Afinal, para ele há uma significação objetiva, dada aos homens, da qual eles

\footnotetext{
${ }^{3}$ Recentemente, muitos autores têm discutido a autoria das obras do Círculo de Bakhtin, e há quem diga que a autoria de algumas obras já foi definitivamente estabelecida. Sobre este problema, remetemos à leitura de $\mathrm{T}$. Bubovna (2009). Segundo a autora, com quem concordamos, esse problema está longe de encontrar solução.
} Disponível em: http://seer.fclar.unesp.br/casa 
devem se apropriar e na qual eles devem exprimir suas subjetividades. Mas a orientação de nosso artigo foi outra. Há, claro, alguma significação objetiva, uma língua exterior ao homem e legada a ele pela história; mas essa língua, como o Círculo mostra em seus trabalhos, subverte-se e atualiza-se em uso. Mesmo encarar a fixação de traços históricos no gênero é encarar sua produção, não seu estado final; encará-lo como produto legado pela história exige a capacidade de vê-lo como totalidade inacabada, ou seja, como totalidade que guarda em si as contradições que o impulsionarão rumo à mudança.

A psicologia de Leontiev traz explicações que podem esclarecer o conceito de gêneros do discurso, e fazer enxergar mais nitidamente o modo como ele opera suas coerções sobre os enunciados individuais, pressionando-os no sentido da realização de uma forma social. Esperamos que essas reflexões - que, evidentemente, não esgotam nenhum dos pontos levantados nos estreitos limites deste artigo - possam ser frutíferas para a problematização de alguns aspectos dos estudos de gêneros do discurso.

\section{Referências bibliográficas}

BAKHTIN, M. Apontamentos de 1970-71. In: Estética da criação verbal. 2. ed.Trad. Maria Ermentina Galvão Pereira. São Paulo: Martins Fontes, 1997a.

Os gêneros do discurso. In:

Estética da criação verbal. 2.ed.Trad. Maria Ermentina Galvão Pereira. São Paulo: Martins Fontes, 1997b.

Problemas da poética de Dostoievski. 2.ed. Trad. Paulo Bezerra. Rio de Janeiro: Forense Universitária, 1997c.

O Freudismo. Trad.Paulo Bezerra. São Paulo: Editora Perspectiva, 2001.

BAKHTIN, M./VOLOSHINOV. Marxismo e filosofia da linguagem. Trad. Michel Lahud e Yara Frateschi Vieira. São Paulo: Hucitec, 1999.

BRONCKART, J-P. Atividade de linguagem, textos e discursos: por um interacionismo sociodiscursivo. Trad. Anna Raquel Machado e Péricles da Cunha. São Paulo: Educ, 1999.

BUBOVNA, T. Voloshinov: a palavra na vida e a palavra na poesia. Trad. Fernando Legón e Diana Araújo Pereira. In: BRAIT, B. (org.) Bakhtin e o círculo. São Paulo: Contexto, 2009.

DUARTE, N. Formação do indivíduo, consciência e alienação: o ser humano na psicologia de A. N. Leontiev. In: Cad. Cedes, Campinas, vol. 24, n. 62, abril de 2004, p.44-63.

ENGELS, F. Do Socialismo Utópico ao Socialismo Científico. In: ENGELS, F. \& MARX, K. Obras escolhidas. Vol.2. São Paulo: Editora Alfa-Ômega.

FAÏTA, D. A noção de gênero discursivo em Bakhtin: uma mudança de paradigma. Trad. Maria Sabina Kundman e Nina A. Mabuchi Miyaki. In: BRAIT, B. (org.). Bakhtin, Dialogismo e Construção do Sentido. Campinas: Editora da Unicamp, 1997.

LEONTIEV, A. O desenvolvimento do psiquismo. Trad. Manuel Dias Duarte. Lisboa: Livros Horizonte, 1978.

MARX, K.; ENGELS, F. A ideologia alemã. 11.ed. Trad. José Carlos Bruni e Marco Aurélio Nogueira. São Paulo: Hucitec, 1999.

PONZIO, A. A revolução bakhtiniana. Trad. Valdemir Miotello. São Paulo: Contexto, 2008. 
CASA, Vol.9 n.1, julho de 2011

RODRIGUES, R. H. Os gêneros do discurso na perspectiva dialógica de linguagem: a abordagem de Bakhtin. In: MEURER, J. L.; MOTTA-ROTH, D.; BONINI, A. (Org.) Gêneros: teorias, métodos, debates. São Paulo: Parábola Editorial, 2005.

ROJO, R. Gêneros do discurso e gêneros textuais: questões teóricas e aplicadas. In:

Gêneros: teorias, métodos, debates. São Paulo: Parábola Editorial, 2005.

SCHNEUWLY, B. Gêneros e tipos de discurso: considerações psicológicas e ontogenéticas. Trad.Roxane Rojo e Glaís Sales Cordeiro. In: ROJO, R. \& CORDEIRO, G. S. (Org.) Gêneros orais e escritos na escola. São Paulo: Mercado de Letras, 2004.

VIGOTSKI, L. S. A formação social da mente. 4.ed. Trad. José Cipolla Neto, Luis Silveira Menna Barreto e Solange Castro Afeche. São Paulo: Martins Fontes, 1991.

Pensamento e linguagem. $2^{a}$ edição. Trad. Jefferson Luiz Camargo. São Paulo: Martins Fontes, 1998. 